\title{
Visible-light-induced Dearomatization via [2+2] Cycloaddition or 1,5-Hydrogen Atom Transfer: Regulating Reaction Pathways of Diradicals on Excited States
}

\author{
Min Zhu, ${ }^{+, \neq}$Xiao Zhang, ${ }^{*,+, \S}$ Chao Zheng, ${ }^{*,+}$ and Shu-Li You ${ }^{*,+,+}$ \\ 'State Key Laboratory of Organometallic Chemistry, Center for Excellence in Molecular Synthesis, Shanghai Institute of Organic \\ Chemistry, University of Chinese Academy of Sciences, Chinese Academy of Sciences, 345 Lingling Lu, Shanghai 200032, China \\ ${ }^{\ddagger}$ School of Physical Science and Technology, ShanghaiTech University, 100 Haike Road, Shanghai 201210, China \\ ${ }^{\S}$ Fujian Key Laboratory of Polymer Science, Fujian Provincial Key Laboratory of Advanced Materials Oriented Chemical Engineering, \\ College of Chemistry and Materials Science, Fujian Normal University, 32 Shangsan Lu, Fuzhou 350007, China
}

\begin{abstract}
Visible-light-induced dearomatization reaction via energy transfer mechanism is an emerging strategy for the synthesis of highly strained polycyclic molecules. Transient, high-energy diradical species on excited states are typically involved in this type of reactions as key intermediates. Herein, we report the visible-light-induced divergent dearomatization of indole-tethered O-methyl oximes, in which the reactivity of the open-shelled singlet diradical intermediates towards competitive reaction pathways, namely [2+2] cycloaddition and 1,5 -hydrogen atom transfer, can be well regulated. The mechanism has been well supported by a series of experimental and computational investigations. The dearomatization reactions allow the facile synthesis of structurally appealing indoline-fused azetidines and related polycyclic molecules with high efficiency and exclusive selectivity.
\end{abstract}

\section{INTRODUCTION}

Regulating the reactivities of key intermediates towards competitive reaction pathways is among the cutting-edge research topics in modern organic chemistry. In this regard, the kinetic vs. thermodynamic control of reactions is a frequently encountered situation where the distribution of products is influenced by both the relative barrier heights and the stability of each product. Although significant efforts have been devoted to manipulating the various selectivities of ground state reactions, yet the control of the reaction pathways of transient, high-energy species on excited states remains underdeveloped. ${ }^{1}$

Recently, visible-light-induced dearomative [2+2] cycloaddition reactions via energy transfer mechanism have attracted broad interests due to the distinct reactivities on excited states leading to target molecules usually prohibited under thermal conditions. ${ }^{2,3,4}$ Mediated by properly selected photosensitizers, aromatic substrates can be excited and coupled with various unsaturated functionalities such as alkenes, ${ }^{5}$ alkynes, ${ }^{6}$ and allenes, ${ }^{7}$ delivering highly strained polycyclic structures that are not easily accessed otherwise. Mechanistically, these reactions proceed in a stepwise manner, involving diradical species on triplet or open-shelled singlet state. ${ }^{8}$ We envisioned that if multiple reaction pathways are available for such diradical intermediates, and at the meantime, their reactivities can be fully manipulated, new opportunities will emerge for convenient synthesis of diverse polycyclic products from the same starting materials under mild conditions. However, to the best of our knowledge, no precedent of such kind was known in the literature.
Scheme 1. Regulating Reaction Pathways of Open-shelled Singlet Diradicals: [2+2] Cycloaddition vs. 1,5-Hydrogen Atom Transfer.

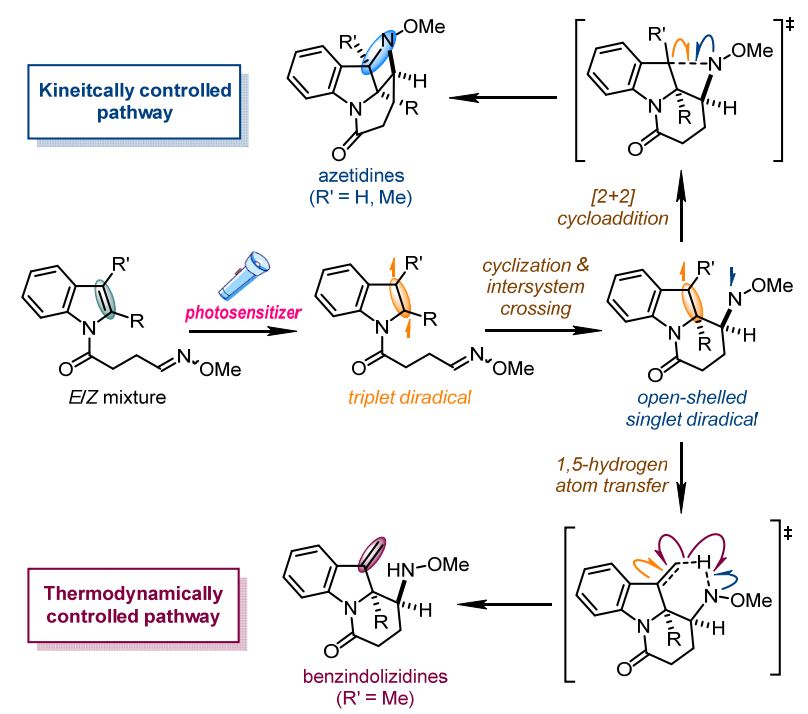

Here we report the visible-light-induced divergent dearomatization reactions of indole-tethered $\mathrm{O}$-methyl oximes initiated with the energy transfer process (Scheme 1). The $[2+2]$ cycloadditions with the $\mathrm{C}=\mathrm{N}$ double bond of the oxime moiety as the diradical acceptors afford structurally appealing indoline-fused azetidine derivatives. ${ }^{9}$ More intriguingly, if an appropriate alkyl substituent is available at the $\mathrm{C} 3$ position of the indole ring, the $[2+2]$ cycloadditions can be interrupted by 1,5 -hydrogen atom transfer of the open-shelled sin- 
glet diradical intermediates, delivering functionalized benzindolizidines. DFT calculations and control experiments suggested that the formations of azetidine and benzindolizidine products are under kinetic and thermodynamic controls, respectively. Guided with these mechanistic insights, the complete switch of the reaction pathways for the open-shelled singlet diradical intermediates were realized, affording each type of products with exclusive selectivity. ${ }^{10}$

\section{RESULTS AND DISCUSSION}

Reaction development. Our study commenced with the evaluation of various reaction parameters using indole-tethered O-methyl oxime 1a $(E / Z$ mixture) as the model substrate (Table 1$)$. According to the calculated triple-singlet energy gap of $\mathbf{1 a}\left[\Delta G\left(\mathrm{~T}_{1}-\mathrm{S}_{0}\right)=\right.$ $54.4 \mathrm{kcal} / \mathrm{mol}$ ], Ir-based photosensitizer $\operatorname{Ir}(\mathrm{dFppy})_{3}$ [1 $\mathrm{mol} \%$, $\left.\Delta G\left(\mathrm{~T}_{1}-\mathrm{S}_{0}\right)=63.5 \mathrm{kcal} / \mathrm{mol}\right]$ was employed under the irradiation of $24 \mathrm{~W}$ blue LEDs at room temperature (See the Supporting Information for the results with other photosensitizers). The dearomative $[2+2]$ reaction of $1 \mathrm{a}(0.1 \mathrm{M})$ proceeded smoothly in a variety of solvents including $\mathrm{MeOH}, \mathrm{MeCN}, \mathrm{DCM}$, acetone, DMF and DMSO (entries 1-6), with DCM as the optimal choice. When the reaction was conducted in a diluted solution of DCM $(0.01 \mathrm{M})$, the desired dearomative $[2+2]$ cycloadduct $\mathbf{2} \mathbf{a}$ was isolated as a single diastereoisomer in excellent yield $(98 \%,>20: 1 \mathrm{dr}$ ) in $3 \mathrm{~h}$ (entry 7 ). Control experiments proved that both the photosensitizer and light are essential for promoting the reaction (entries 8 and 9).

Scheme 2. Substrate Scope: Dearomative $[2+2]$ Cycloaddition $^{a}$
Table 1. Optimization of Reaction Conditions for Dearomative $[2+2]$ Cycloaddition $^{a}$

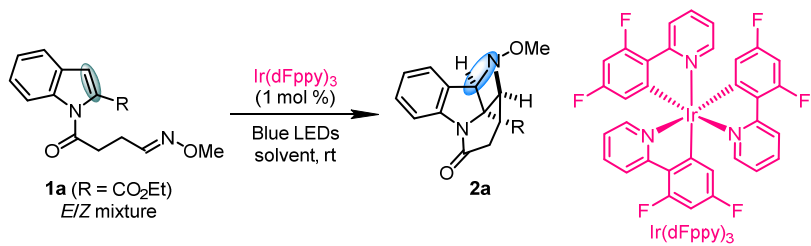

\begin{tabular}{llll}
\hline Entry & solvent & time $(\mathrm{h})$ & yield of $\mathbf{2 a}(\%)^{b}$ \\
\hline 1 & $\mathrm{MeOH}$ & 3 & 9 \\
2 & $\mathrm{MeCN}$ & 3 & 12 \\
3 & DCM & 3 & 95 \\
4 & acetone & 3 & 90 \\
5 & DMF & 3 & 85 \\
6 & DMSO & 3 & 92 \\
$7^{c}$ & DCM & 3 & quant. $\left(98^{d}\right)$ \\
$8^{e}$ & DCM & 24 & 0 \\
$9^{f}$ & DCM & 24 & 0 \\
\hline
\end{tabular}

${ }^{a}$ Reaction conditions: $1 \mathrm{a}(0.1 \mathrm{mmol})$ and photosensitizer $(1 \mathrm{~mol} \%)$ in solvent $(c=0.1 \mathrm{M})$ were irradiated by $24 \mathrm{~W}$ blue LEDs $(450 \mathrm{~nm})$ at room temperature under argon. ${ }^{b} \mathrm{NMR}$ yield using $\mathrm{CH}_{2} \mathrm{Br}_{2}$ as the internal standard. ${ }^{c} c=0.01$ M. ${ }^{d}$ Isolated yield. ${ }^{e}$ Without photosensitizer. ${ }^{f}$ In dark.
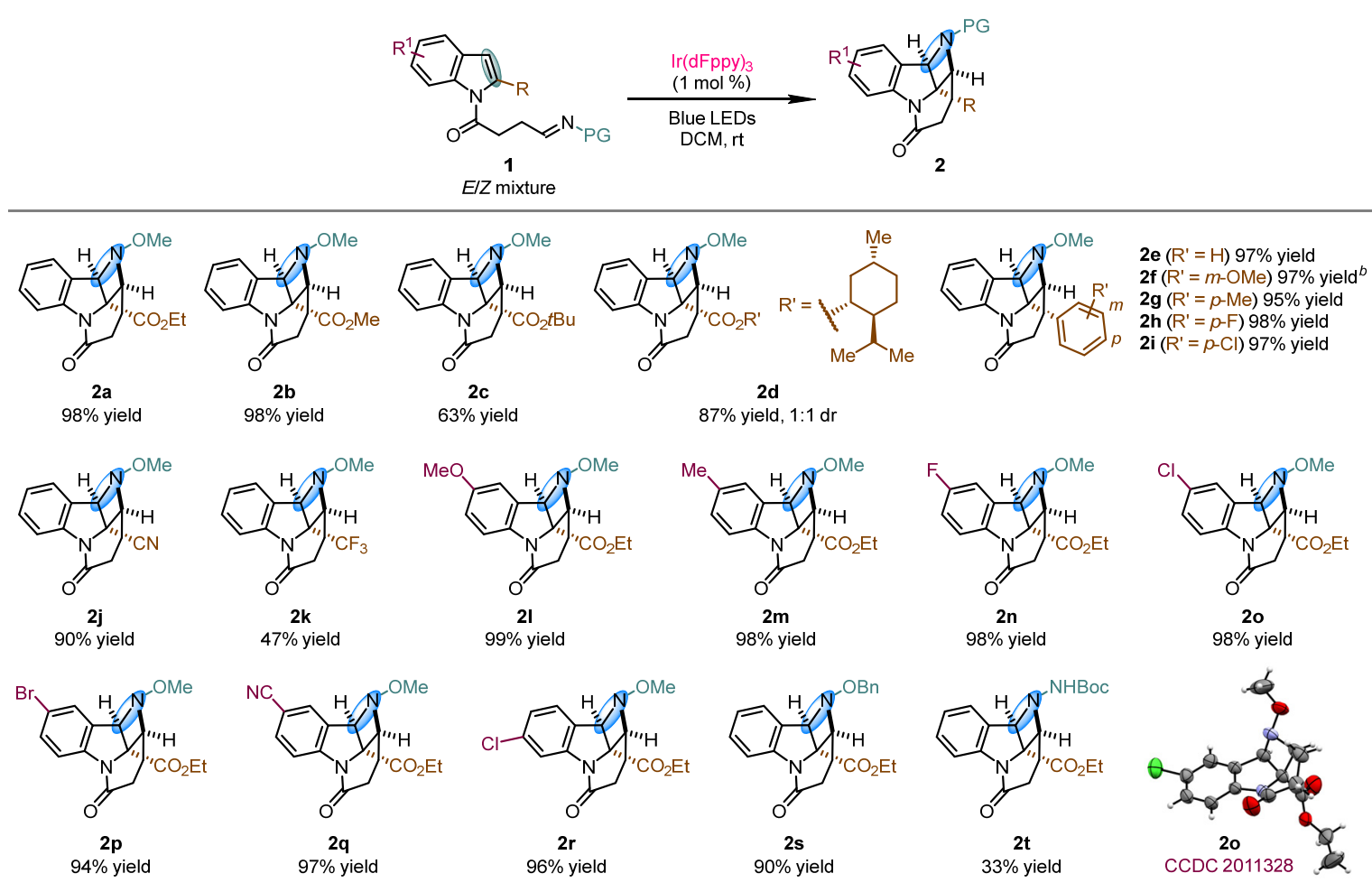

${ }^{a}$ Reaction conditions: $1(0.2 \mathrm{mmol})$ and $\operatorname{Ir}(\mathrm{dFppy})_{3}(1 \mathrm{~mol} \%)$ in DCM $(c=0.01 \mathrm{M})$ were irradiated by $24 \mathrm{~W}$ blue LEDs $(450 \mathrm{~nm})$ at room temperature under argon for $8 \mathrm{~h} .{ }^{b}$ The reaction was quenched after $48 \mathrm{~h}$. 
With the optimal conditions (Table 1, entry 7 ) in hands, the scope of the visible-light-induced dearomative $[2+2]$ cycloaddition reaction was investigated (Scheme 2 ). The reaction conditions tolerate a large array of indole-tethered $\mathrm{O}$-methyl oximes, leading to the corresponding polycyclic indoline-fused azetidines. In line with our previous observations, ${ }^{5 \mathrm{a}, 6 \mathrm{~b}}$ an electron-deficient substituent (esters, 2a2d, $63-98 \%$ yields; cyano, $\mathbf{2 j}$, $90 \%$ yield; trifluoromethyl, $\mathbf{2 k}, 47 \%$ yield) or an aryl group (2e-2i, $95-98 \%$ yields) at the C2 position of the indole ring are beneficial for the reactions. In particular, compound $\mathbf{2 d}$, consisting of the ester group derived from L-menthol, was obtained as a pair of diastereoisomers $(1: 1 \mathrm{dr})$. Substituents of varied electronic properties like methoxy (21, 99\% yield), methyl (2m, $98 \%$ yield), halogen atoms ( $\mathbf{2 n - 2 p}$ and $\mathbf{2 r}$, $94-98 \%$ yields) and cyano (2q, 97\% yield) at either C5 or C6 position of the indole ring are also compatible. The X-ray crystallographic analysis of $\mathbf{2 0}$ confirmed that the fused tricyclic structure of the target molecules adopted the all-cis configuration. The switch to O-Bn oxime analog did not affect the reaction outcomes in that azetidine $2 \mathrm{~s}$ was delivered in $90 \%$ yield. To be noted, indole-tethered N-Boc hydrazone could also participate in the dearomative $[2+2]$ cycloaddition reaction, albeit with moderate yield of $2 \mathbf{t}$ (33\%).

Scheme 3. Substrate Scope: Dearomative 1,5-Hydrogen Atom Transfer $^{a}$
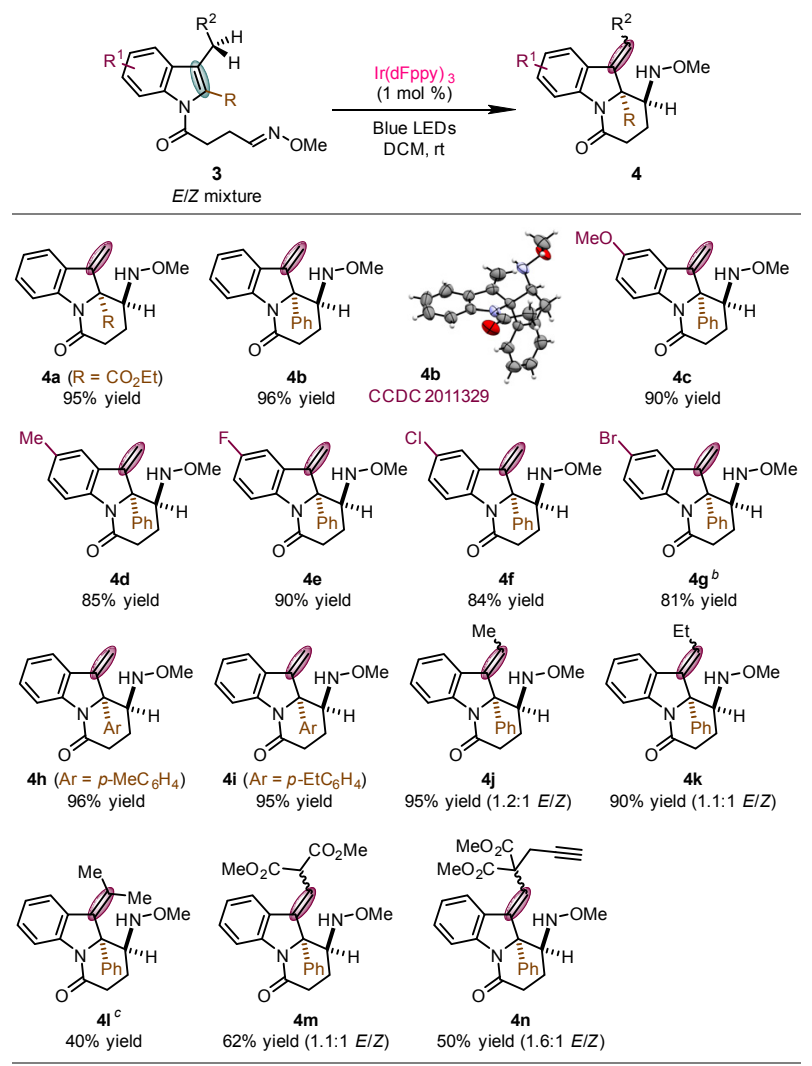

${ }^{a}$ Reaction conditions: $3(0.2 \mathrm{mmol})$ and $\operatorname{Ir}(\mathrm{dFppy})_{3}(1 \mathrm{~mol} \%)$ in $\operatorname{DCM}(c=0.01 \mathrm{M})$ were irradiated by $24 \mathrm{~W}$ blue LEDs $(450 \mathrm{~nm})$ at room temperature under argon for $24 \mathrm{~h}^{b}{ }^{b}$ The reaction was quenched after 12 h. ${ }^{c} 405 \mathrm{~nm}$ LEDs were used.

On the other hand, distinct reactivity was observed for substrates 3 bearing an alkyl substituent at the $\mathrm{C} 3$ position of the indole ring (Scheme 3). The $[2+2]$ cycloaddition pathway was interrupted after the first $\mathrm{C}-\mathrm{C}$ bond formation at the $\mathrm{C} 2$ position. A formal 1,5-hydrogen atom transfer process furnished an O-methyl hydroxylamine moiety and an exocyclic $\mathrm{C}=\mathrm{C}$ double bond at the benzindolizidine skeleton. For C3-methyl substituted substrates, the formation of such functionalized benzindolizidines $\mathbf{4 a - 4 i}$ as a single diastereoisomer under the standard conditions for 12-24 h (81-96\% yields, $>20: 1 \mathrm{dr}$ ). Besides the ester group or the aromatic substituent at the $\mathrm{C} 2$ position, the reactions further tolerated functional groups such as methoxy, methyl or halogen atoms at the C5 position of the indole ring. The $\mathrm{X}$-ray crystallographic analysis of $\mathbf{4} \mathbf{b}$ confirmed that the O-methyl hydroxylamine moiety and the C2-substituent are in the anti configuration. For the substrates with a longer alkyl chain at the $\mathrm{C} 3$ position, the corresponding products $4 \mathbf{j}, 4 \mathbf{k}$ and $4 \mathbf{m}$ were isolated as a mixture of geometric isomers of olefins (62-95\% combined yields, 1.1:1-1.2:1 E/Z). Interestingly, when a C3-tethered terminal alkyne side chain and an $\mathrm{N}$-tethered O-methyl oxime moiety are available at the same time, the functionalized benzindolizidine $4 \mathrm{n}$ was delivered as the only product ( $50 \%$ yield, $1.6: 1 \mathrm{E} / \mathrm{Z}$ ), while the corresponding dearomative $[2+2]$ cycloaddition with the terminal alkyne towards a cyclobutene derivative was not observed. The reaction with C3-isopropyl substituted substrate was less efficient. The utilization of $405 \mathrm{~nm}$ LEDs was required to guarantee a moderate yield of $\mathbf{4 1}$ (40\%).

Mechanistic studies. To shed light on the mechanism of the visible-light induced dearomatization of indole-tethered O-methyl oximes, a series of control experiments were performed. First, cyclic voltammetry measurement and triplet quenching experiment of $\mathbf{1 a}$ suggested that the reaction proceeded through the energy transfer process via triplet state intermediate rather than the photoredox mechanism (See the Supporting Information for details). Previously, the $[2+2]$ photocycloaddition reactions involving imines were generally initiated with the excitation of the $\mathrm{C}=\mathrm{N}$ double bond. ${ }^{9 \mathrm{c}} \mathrm{How}-$ ever, in this case, the reaction was triggered by the excitation of the indole core, as in Stern-Volmer luminescence quenching experiments 1 a readily quenched the photosensitizer $\operatorname{Ir}(\mathrm{dFppy})_{3}$, but its indoline analog 1a' did not (Figure 1).

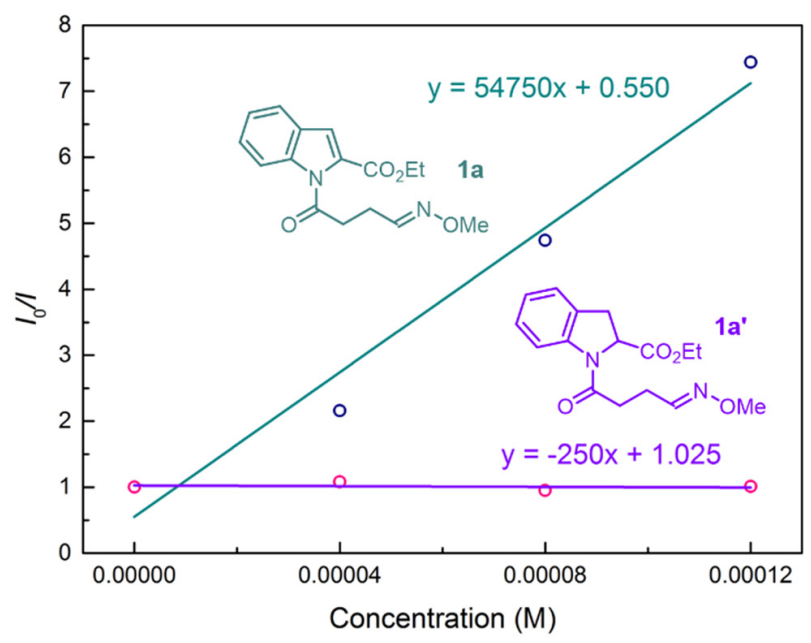

Figure 1. Stern-Volmer quenching experiments with photoexcited $\operatorname{Ir}(\mathrm{dFppy})_{3}\left(0.02 \mathrm{mM}, \lambda_{\mathrm{ex}}=335 \mathrm{~nm}, \lambda_{\mathrm{em}}=491 \mathrm{~nm}\right) . I_{0}$ and $I$ are respective luminescence intensities in the absence and presence of the indicated concentration of $\mathbf{1} \mathbf{a}$ or $\mathbf{1} \mathbf{a}^{\prime}$. 
In order to explore the energy profile of the dearomative $[2+2]$ cycloaddition and the 1,5-hydrogen atom transfer reactions, DFT calculations were performed. A diagram of simplified energy profiles with $\mathbf{3 a}$ as the model substrate is shown in Figure 2. The excitation of $3 \mathbf{a}$ from the ground state to its first triplet state $\left(\mathbf{3} \mathbf{a}-\mathbf{T}_{\mathbf{1}}\right)$ requires an energetic uphill of $53.0 \mathrm{kcal} / \mathrm{mol}$. In line with the Stern-Volmer luminescence quenching experiments, and also what was observed in the previous dearomative $[2+2]$ cycloaddition reactions via energy transfer mechanism, ${ }^{5,6 b}$ the two spin-paralleled electrons of 3a$\mathbf{T}_{\mathbf{1}}$ are mainly populated at the $\mathrm{C} 2$ and $\mathrm{C} 3$ positions of the indole ring, with an elongated $\mathrm{C} 2-\mathrm{C} 3$ bond $(1.51 \AA$ ). The oximes in both $E$ and $Z$ configurations are found reactive towards the cyclization with the C2 position of the indole ring (See the Supporting Information for details). The diastereoselectivity of the reaction was determined in this step. The $\mathrm{C}-\mathrm{C}$ bond formation between the $\mathrm{Si}$-face of the $\mathrm{C} 2$ position of the indole ring and the Re-face of the oxime via TS1 (62.7 $\mathrm{kcal} / \mathrm{mol}$, $9.7 \mathrm{kcal} / \mathrm{mol}$ relative to $\left.3 \mathbf{a}-\mathbf{T}_{\mathbf{1}}\right)$ was more preferential than the $\mathrm{Si}$-face-Si-face bond formation via TS1' $(64.5 \mathrm{kcal} / \mathrm{mol}, 11.5$ $\mathrm{kcal} / \mathrm{mol}$ relative to $\mathbf{3 a}-\mathbf{T}_{\mathbf{1}}$ ), which is consistent with the anti configuration of the $\mathrm{C} 2$-substituent and the $\mathrm{O}$-methyl hydroxylamine moiety in 4a. The triplet diradical INT1 $(38.4 \mathrm{kcal} / \mathrm{mol})$ was further transformed to the corresponding open-shelled singlet diradical species INT1-OSS (38.2 kcal/mol) via minimal energy crossing point
MECP1 $(42.2 \mathrm{kcal} / \mathrm{mol})$. Notably, there are two competitive reaction pathways available for INT1-OSS. One is the 1,5-hydrogen atom transfer via transition state TS3 $(55.5 \mathrm{kcal} / \mathrm{mol}, 17.3 \mathrm{kcal} / \mathrm{mol}$ relative to INT1-OSS), leading to the experimentally observed product $4 \mathbf{a}(14.9 \mathrm{kcal} / \mathrm{mol})$. The other is the energetically more feasible radical-radical combination via transition state TS2 (41.6 $\mathrm{kcal} / \mathrm{mol}, 3.4 \mathrm{kcal} / \mathrm{mol}$ relative to INT1-OSS), furnishing the dearomative $[2+2]$ cycloaddition product $4 \mathbf{a}^{\prime}(19.6 \mathrm{kcal} / \mathrm{mol})$. It should be mentioned that for substrates 1 without the C3-alkyl substituent, the $[2+2]$ cycloaddition towards products $\mathbf{2}$ is the only reasonable reaction pathway (Scheme 2). However, for C3-alkyl substituted substrates 3 , no such $[2+2]$ cycloaddition product was observed under the conditions reported in Scheme 3 (12-24 h). Considering that the calculated barrier height of TS2 is much lower than that of TS3, and the experimentally observed benzindolizidine product $\mathbf{4 a}$ is more stable than $\mathbf{4 a}$ ', we envisioned that the two reaction pathways of the open-shelled singlet diradical INT1-OSS towards $\mathbf{4 a}$ and $\mathbf{4 a}$ are under kinetic and thermodynamic controls, respectively. Therefore, our calculation results predicted that in the reactions of C3-alkyl substituted substrates 3 , the dearomative $[2+2] \mathrm{cy}-$ cloaddition products like 4a' might also be observed at the early stage of the reaction under kinetic control, but are later transformed into thermodynamically more stable products 4 .

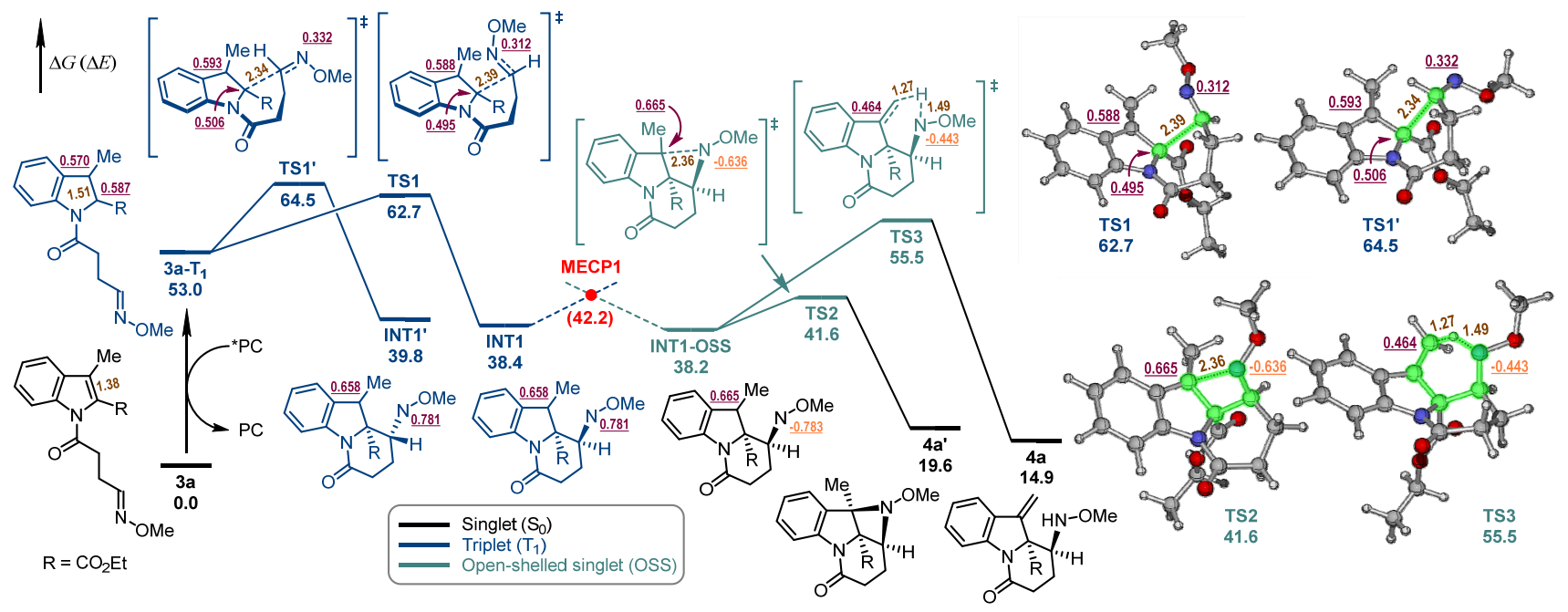

Figure 2. Energy profile of the dearomative [2+2] cycloaddition and the 1,5-hydrogen atom transfer reactions, and the optimized structures of the key transition states. Calculated at $(\mathrm{U}) \mathrm{B} 3 \mathrm{LYP} / 6-31 \mathrm{G}(\mathrm{d}, \mathrm{p})$ level of theory. The Gibbs free energies $(\Delta G)$ or electronic energies $(\Delta E$, in parentheses) are in $\mathrm{kcal} / \mathrm{mol}$. The values in brown are bond distances in angstrom. The underlined values are Mulliken spin populations at certain atoms.

Scheme 4. Isolation and Transformation of Dearomative [2+2] Cycloaddition Product



Bearing this hypothesis in mind, we next tried to characterize the generation and the transformation of dearomative $[2+2]$ cycloaddition product in the reaction of C3-alkyl substituted substrate $\mathbf{3 f}$ by ${ }^{1} \mathrm{H}$ NMR spectroscopy (Scheme 4 and Figure 3). It was found that 3f was almost fully converted to dearomative $[2+2]$ cycloaddition product $\mathbf{4 \mathbf { f } ^ { \prime }}$ within $1 \mathrm{~h} . \mathbf{4 \mathbf { f } ^ { \prime }}$ could be isolated and its structure was confirmed unambiguously by X-ray crystallographic analysis. When the reaction was allowed to further proceed, $\mathbf{4 \mathbf { f } ^ { \prime }}$ was consumed gradually, leading to the temporary regeneration of $\mathbf{3} \mathbf{f}$ and steady accumulation of $\mathbf{4 f}$. After $20 \mathrm{~h}, \mathbf{4 f}$ became the dominant species in the reaction mixture. Notably, $\mathbf{4} \mathbf{f}^{\prime}$ was found stable in the absence of photosensitizer or light irradiation, indicating the hemolytic $\mathrm{C}-\mathrm{N}$ bond cleavage of $\mathbf{4 f}$ is a visible-light-promoted process. Collectively, these observa- 
tions corroborate with the calculation results. Under the optimal reaction conditions [Blue LEDs and $\operatorname{Ir}(\mathrm{dFppy})_{3}$ ], the formation of dearomative $[2+2]$ cycloaddition product $\mathbf{4 f ^ { \prime }}$ from $\mathbf{3} \mathbf{f}$ is fast but reversible. Interestingly, although the ground state Gibbs free energies of the functionalized benzindolizidine products are much higher than that of the starting materials $(\mathbf{4 a}, 14.9 \mathrm{kcal} / \mathrm{mol}$ relative to $\mathbf{3 a})$, they are still the thermodynamically favored species of the system under the reaction conditions.

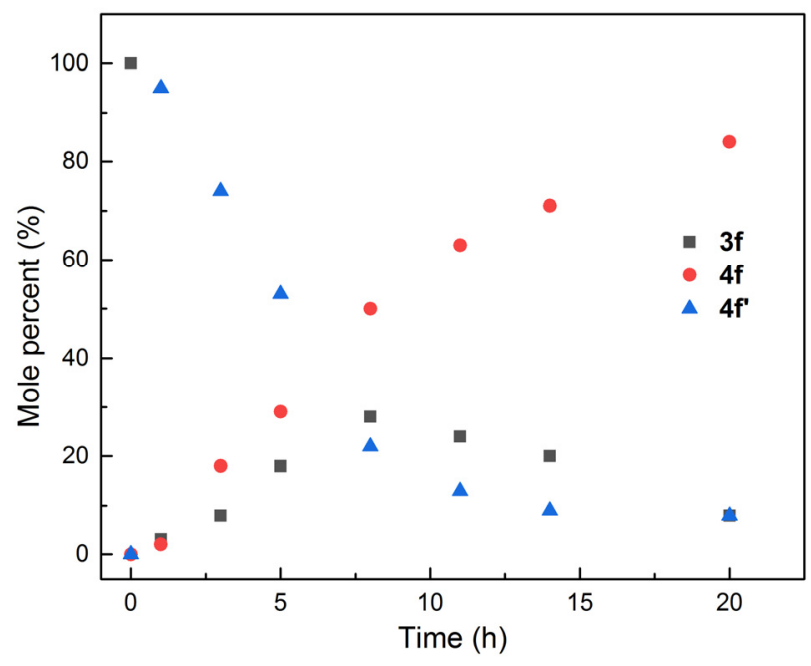

Figure 3. Time-course of the reaction of $\mathbf{3} \mathbf{f}$ shown in eq 1 of Scheme 4 monitored by ${ }^{1} \mathrm{H}$ NMR spectroscopy.

Scheme 5. Dearomative $[2+2]$ Cycloaddition Reactions with C3-Alkyl Substituted Substrates
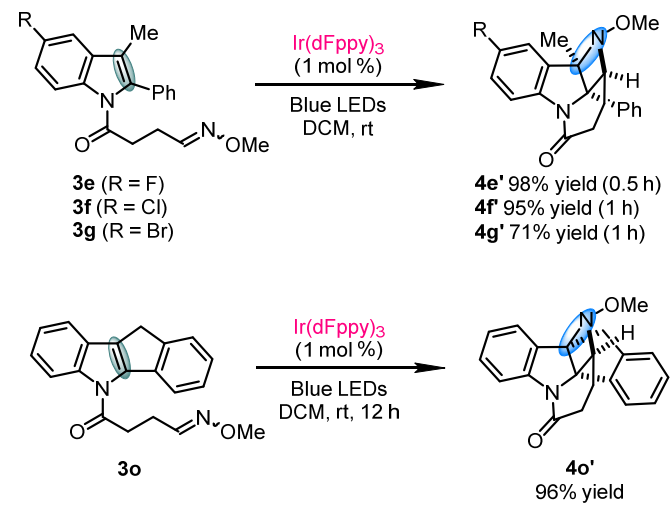

Guided by these mechanistic insights, the complete switch of the reaction pathway from 1,5-hydrogen atom transfer to [2+2] cycloaddition was achieved for a series of C3-alkyl substituted substrates (Scheme 5). For example, when the reactions of C3-methyl substituted substrates bearing a halogen atom the C5 position (3e$3 g$ ) under the standard conditions were quenched at $0.5-1 \mathrm{~h}$, the corresponding $[2+2]$ cycloaddition products $\mathbf{4} \mathbf{e}^{\prime}-\mathbf{4} \mathbf{g}^{\prime}$ could be isolated in $71-98 \%$ yields. Besides, an indene-fused substrate $3 \mathbf{o}$ could also participate in the dearomative $[2+2]$ cycloaddition reaction, leading to 4o' containing a unique 4,5,5,6-tetracyclic core structure in $96 \%$ yield. Notably, the 1,5 -hydrogen atom transfer process was not possible here due to the conformational restriction in this bridged-ring structure. Therefore, compound 4o' could stay intact for a longer reaction time $(12 \mathrm{~h})$.
Synthetic utilities. In order to demonstrate the synthetic potential of the dearomative reactions reported herein, the gram-scale synthesis of the two types of dearomative products and their derivations were demonstrated (Scheme 6). The reactions of $\mathbf{1 a}$ and $\mathbf{3 a}$ could be performed in more concentrated DCM solution $(c=0.1$ or 0.05 $\mathrm{M})$, affording the target molecules on gram scale (2a, $92 \%$ yield, 1.10 $\mathrm{g}$ and $\mathbf{4 a}, 84 \%$ yield, $0.92 \mathrm{~g}$ ). When treated with $\mathrm{LiOH} \cdot \mathrm{H}_{2} \mathrm{O}$, compound 2a underwent cascade saponification, decarboxylation and $\mathrm{C}-\mathrm{N}$ bond cleavage reactions, delivering the corresponding $\mathrm{O}-\mathrm{me}-$ thyl hydroxylamine 5 in $72 \%$ yield. On the other hand, the exocyclic $\mathrm{C}=\mathrm{C}$ double bond of $\mathbf{4 a}$ could be hydrogenated with $\mathrm{Pd} / \mathrm{C}$. The indoline product 6 was obtained as a pair of diastereoisomer in $85 \%$ combined yield with 1:1 dr. In addition, the saponification of $\mathbf{4 a}$ with $\mathrm{LiOH}$ in $\mathrm{THF} / \mathrm{H}_{2} \mathrm{O}$ initiated a cascade reaction towards polycyclic tetrahydro- $\beta$-carboline 7 in $61 \%$ yield, whose structure was determined by X-ray crystallographic analysis.

Scheme 6. Gram-scale Reactions and Product Derivations



\section{CONCLUSION}

In this work, we have developed visible-light-induced divergent dearomatization reactions of indole-tethered O-methyl oximes via energy transfer mechanism. Two reaction pathways, namely, [2+2] cycloaddition and 1,5-hydrogen atom transfer, are available for the key diradical intermediate on the open-shelled singlet state. Mechanistic studies revealed that the two reaction pathways are under kinetic and thermodynamic controls, respectively. By tuning the substitution patterns of the substrates or the reaction conditions, the two reaction pathways of the open-shelled singlet diradical species can be well regulated, allowing the facile synthesis of structurally appealing indoline-fused azetidine derivatives and functionalized benzindolizidines with high efficiency and exclusive selectivity. Currently we are working on expanding the scope of manipulating the reactivity of high-energy intermediates on excited states, towards the expedient synthesis of diverse highly strained polycyclic molecules.

\section{ASSOCIATED CONTENT}


The Supporting Information is available free of charge on the ACS Publications website at $\mathrm{xxx}$.

Experimental procedures and analysis data for all new compounds and computational details (PDF)

X-ray crystallographic data for compound 20 (CIF)

X-ray crystallographic data for compound $\mathbf{4 b}$ (CIF)

$\mathrm{X}$-ray crystallographic data for compound $\mathbf{4 f ^ { \prime }}$ (CIF)

$\mathrm{X}$-ray crystallographic data for compound 7 (CIF)

\section{AUTHOR INFORMATION}

\section{Corresponding Author}

*zhangxiao@sioc.ac.cn

* zhengchao@sioc.ac.cn

*slyou@sioc.ac.cn

\section{ORCID}

Chao Zheng: 0000-0002-7349-262X

Shu-Li You: 0000-0003-4586-8359

\section{Notes}

The authors declare no competing financial interest.

\section{ACKNOWLEDGMENT}

We thank MOST (2016YFA0202900), NSFC (21772219, 21821002, 21801248), Science and Technology Commission of Shanghai Municipality (18JC1411302, 18QA1404900, 18YF1428900), Chinese Academy of Sciences (XDB20030000, QYZDY-SSWSLH012), and Youth Innovation Promotion Association (2017302, 2019255) of CAS for generous financial support. S.-L.Y. acknowledges the support from the Tencent Foundation through the XPLORER PRIZE.

\section{REFERENCES}

(1) For selected examples: (a) Andrew, D.; Hastings, D. J.; Oldroyd, D. L.; Rudolph, A.; Weedon, A. C.; Wong, D. F.; Zhang, B. Triplet 1,4-biradical intermediates in the photocycloaddition reactions of enones and $\mathrm{N}$-acylindoles with alkenes. Pure Appl. Chem. 1992, 64, 1327. (b) Andrew, D.; Weedon, A. C. Determination of the Relative Rates of Formation, Fates, and Structures of Triplet 1,4-Biradicals Generated in the Photochemical Cycloaddition Reactions of 2-Cyclopentenones with 2-Methylpropene. J. Am. Chem. Soc. 1995, 117, 5647. (c) Lu, S.-C.; Duan, X.-Y.; Shi, Z.-J.; Li, B.; Ren, Y.-W.; Zhang, W.; Zhang, Y.-H.; Tu, Z.-F. Photoinduced Intramolecular Addition of 3-Acyl-2-haloindoles to Alkenes. Org. Lett. 2009, 11, 3902. (d) Ahuja, S.; Raghunathan, R.; Kumarasamy, E.; Jockusch, S.; Sivaguru, J. Realizing the Photoene Reaction with Alkenes under Visible Light Irradiation and Bypassing the Favored [2+2]-Photocycloaddition. J. Am. Chem. Soc. 2018, 140, 13185. Addition and correction: J. Am.. Chem. Soc. 2019, 141, 12946.

(2) For selected reviews on dearomatization reactions: (a) Pape, A. R.; Kaliappan, K. P.; Kündig, E. P. Transition-Metal-Mediated Dearomatization Reactions. Chem. Rev. 2000, 100, 2917. (b) Roche, S. P.; Porco, J. A. Dearomatization strategies in the synthesis of complex natural products. Angew. Chem. Int. Ed. 2011, 50, 4068. (c) Zhuo, C.-X.; Zhang, W.; You, S.-L. Catalytic asymmetric dearomatization reactions. Angew. Chem. Int. Ed. 2012, 51, 12662. (d) Repka, L. M.; Reisman, S. E. Recent developments in the catalytic, asymmetric construction of pyrroloindolines bearing all-carbon quaternary stereocenters. J. Org. Chem. 2013, 78, 12314. (e) Zhuo, C.-X.; Zheng, C.; You, S.-L. Transition-metal-catalyzed asymmetric allylic dearomatization reactions. Acc. Chem. Res. 2014, 47, 2558. (f) Roche, S. P.; Tendoung, J.-J. Y.; Tréguier, B. Advances in dearomatization strategies of indoles. Tetrahedron 2015, 71, 3549. (g) Zheng, C.; You, S.-L. Catalytic Asymmetric Dearomatization by Transition-Metal-Catalysis: A Method for Transformations of Aromatic Compounds. Chem 2016, 1, 830. (h) James, M. J.;
O'Brien, P.; Taylor, R. J. K.; Unsworth, W. P. Synthesis of spirocyclic indolenines. Chem. Eur. J. 2016, 22, 2856. (i) Bariwal, J.; Voskressensky, L. G.; Van der Eycken, E. V. Recent advances in spirocyclization of indole derivatives. Chem. Soc. Rev. 2018, 47, 3831. (j) Wertjes, W. C.; Southgate, E. H.; Sarlah, D. Recent advances in chemical dearomatization of nonactivated arenes. Chem. Soc. Rev. 2018, 47, 7996. (k) Cheng, Y.-Z.; Zhang, X.; You, S.-L. Visible-Light-Mediated Photocatalysis as a New Tool for Catalytic Asymmetric Dearomatization (CADA) Reactions. Sci. Bull. 2018, 63, 809. (1) Huang, G.; Yin, B. Recent developments in transition-metal-catalyzed dearomative cyclizations of indoles as dipolarophiles for the construction of indolines. Adv. Synth. Catal. 2019, 361, 405. (m) Festa, A. A.; Voskressensky, L. G.; Van der Eycken, E. V. Visible light-mediated chemistry of indoles and related heterocycles. Chem. Soc. Rev. 2019, 48, 4401. (n) Okumura, M.; bach, D. VisibleLight-Induced Dearomatizations. Eur. J. Org. Chem. 2020, 2020, 1259. (p) Zhu, M.; Zhang, X.; You, S.-L. Visible-light-promoted Dearomatization of Benzene and Derivatives. Chem. J. Chin. Univ. 2020, 41, 1407. (o) Huck, C. J.; Sarlah, D. Shaping Molecular Landscapes: Recent Advances, Opportunities, and Challenges in Dearomatization Chem 2020, DOI: 10.1016/j.chempr.2020.06.015.

(3) For selected reviews on photocycloaddition: (a) McCullough, J. J. Photoadditions of Aromatic Compounds. Chem. Rev. 1987, 87, 811. (b) Inoue, Y. Asymmetric Photochemical Reactions in Solution. Chem. Rev. 1992, 92, 741. (c) Cornelisse, J. The Meta Photocycloaddition of Arenes to Alkenes. Chem. Rev. 1993, 93, 615. (d) Bach, T.; Hehn, J. P. Photochemical Reactions as Key Steps in Natural Product Synthesis. Angew. Chem. Int. Ed. 2011, 50, 1000. (e) Prier, C. K.; Rankic, D. A.; MacMillan, D.W. C. Visible light Photoredox Catalysis with Transition Metal Complexes: Applications in Organic Synthesis. Chem. Rev. 2013, 113, 5322. (f) Yoon, T. P. Visible Light Photocatalysis: The Development of Photocatalytic Radical Ion Cycloadditions. ACS Catal. 2013, 3, 895. (g) Xuan, J.; Lu, L.-Q.; Chen, J.-R.; Xiao, W.-J. Visible-Light-Driven Photoredox Catalysis in the Construction of Carbocyclic and Heterocyclic Ring Systems. Eur.J. Org. Chem. 2013, 2013, 6755. (h) Poplata, S.; Tröster, A.; Zou, Y.-Q.; Bach, T. Recent Advances in the Synthesis of Cyclobutanes by Olefin [2+2] Photocycloaddition Reactions. Chem. Rev. 2016, 116, 9748. (i) Remy, R; Bochet, C. G. Arene-Alkene Cycloaddition. Chem. Rev. 2016, 116, 9816. (j) Ramamurthy, V.; Sivaguru, J. Supramolecular Photochemistry as a Potential Synthetic Tool: Photocycloaddition. Chem. Rev. 2016, 116, 9914. (k) Romero, N. A.; Nicewicz, D. A. Organic Photoredox Catalysis. Chem. Rev. 2016, 116, 10075. (1) Yoon, T. P. Photochemical Stereocontrol using Tandem Photoredox-Chiral Lewis Acid Catalysis. Acc. Chem. Res. 2016, 49, 2307. (m) Huang, X.; Meggers, E. Asymmetric Photocatalysis with Bis-Cyclometalated Rhodium Complexes. Acc. Chem. Res. 2019, 52, 833.

(4) For recent examples on visible-light-induced dearomatization reactions: (a) Hernandez, L. W.; Klöckner, U.; Pospech, J.; Hauss, L.; Sarlah, D. Nickel-Catalyzed Dearomative trans-1,2-Carboamination. J. Am. Chem. Soc. 2018, 140, 4503. (b) James, M. J.; Schwarz, J. L.; Strieth-Kalthoff, F.; Wibbeling, B.; Glorius, F. Dearomative cascade photocatalysis: divergent synthesis through catalyst selective energy transfer. J. Am. Chem. Soc. 2018, 140, 8624. (c) Guo, Q.; Wang, M.; Liu, H.; Wang, R.; Xu, Z. Visible-LightPromoted Dearomative Fluoroalkylation of $\beta$-Naphthols through Intermolecular Charge Transfer Angew. Chem. Int. Ed. 2018, 57, 4747. (d) Hu, N.; Jung, H.; Zheng, Y.; Lee, J.; Zhang, L.; Ullah, Z.; Xie, X.; Harms, K.; Baik, M.-H.; Meggers, E. Catalytic Asymmetric Dearomatization by Visible-LightActivated [2+2] Photocycloaddition. Angew. Chem. Int. Ed. 2018, 57, 6242. (e) Stegbauer, S.; Jandl, C.; Bach, T. Enantioselective Lewis Acid Catalyzed ortho Photocycloaddition of Olefins to Phenanthrene-9-carboxaldehydes. Angew. Chem. Int. Ed. 2018, 57, 14593. (f) Zhu, M.; Zhou, K.; Zhang, X.; You, S.-L. Visible-Light-Promoted Cascade Alkene Trifluoromethylation and Dearomatization of Indole Derivatives via Intermolecular Charge Transfer. Org. Lett. 2018, 20, 4379. (g) Dong, W.; Yuan, Y.; Gao, X.; Keranmu, M.; Li, W.; Xie, X.; Zhang, Z. Visible-Light-Induced Intermolecular Dearomative Cyclization of 2-Bromo-1,3-dicarbonyl Compounds and Alkynes: Synthesis of Spiro[4.5]deca-1,6,9-trien-8-ones. Org. Lett. 2018, 20, 5762. (h) Wang, Q.; Qu, Y.; Xia, Q.; Song, H.; Song, H.; Liu, Y.; Wang, Q. 
Synthesis of gem-Difluorinated Spiro- $\gamma$-lactam Oxindoles by Visible-LightInduced Consecutive Difluoromethylative Dearomatization, Hydroxylation, and Oxidation. Chem. Eur. J. 2018, 24, 11283. (i) Wang, Q.; Qu, Y.; Xia, Q.; Song, H.; Song, H.; Liu, Y.; Wang, Q. Visible-Light-Mediated Dearomatization/Cyanation Cascade Reaction of Indoles: Access to Highly Functionalized Spiro- $\gamma$-lactam Indolines with Two Contiguous Sterically Congested Quaternary Carbon Stereocenters. Adv. Synth. Catal. 2018, 360, 2879. (j) Wertjes, W. C.; Okumura, M.; Sarlah, D. Palladium-Catalyzed Dearomative syn-1,4-Diamination. J. Am. Chem. Soc. 2019, 141, 163. (k) Bingham, T. W.; Hernandez, L. W.; Olson, D. G.; Svec, R. L.; Hergenrother, P. J.; Sarlah, D. Enantioselective Synthesis of Isocarbostyril Alkaloids and Analogs Using Catalytic Dearomative Functionalization of Benzene. J. Am. Chem. Soc. 2019, 141, 657. (1) Soni, V. K.; Hwang, H. S.; Moon, Y. K.; Park, S. W.; You, Y.; Cho, E. J. Generation of N-Centered Radicals via a Photocatalytic Energy Transfer: Remote Double Functionalization of Arenes Facilitated by Singlet Oxygen. J. Am. Chem. Soc. 2019, 141, 10538. (m) Tang, C.; Okumura, M.; Zhu, Y.; Hooper, A.; Zhou, Y.; Lee, Y.; Sarlah, D. Palladium-Catalyzed Dearomative syn-1,4-Carboamination with Grignard Reagents. Angew. Chem. Int. Ed. 2019, 58, 10245. (n) Cheng, Y. Z.; Zhao, Q. R.; Zhang, X.; You, S.-L. Asymmetric Dearomatization of Indole Derivatives with N-Hydroxycarbamates Enabled by Photoredox Catalysis. Angew. Chem. Int. Ed. 2019, 58, 18069. (o) Ma, J.; Strieth-Kalthoff, F.; Dalton, T.; Freitag, M.; Schwarz, J. L.; Bergander, K.; Daniliuc, C.; Glorius, F. Direct Dearomatization of Pyridines via an Energy-Transfer-Catalyzed Intramolecular [4+2] Cycloaddition. Chem 2019, 5, 2854. (p) Li, H.; Subbotina, E.; Bunrit, A.; Wang, F.; Samec, J. S. M. Functionalized spirolactones by photoinduced dearomatization of biaryl compounds. Chem. Sci. 2019, 10, 3681. (q) Guo, Y.; Nguyen, T. V.; Koenigs, R. M. Norcaradiene Synthesis via Visible-LightMediated Cyclopropanation Reactions of Arenes. Org. Lett. 2019, $21,8814$. (r) Dai, W.; Geib, S. J.; Curran, D. P. 1,4-Hydroboration Reactions of Electron-Poor Aromatic Rings by N-Heterocyclic Carbene Boranes. J. Am. Chem. Soc. 2020, 142, 6261. (s) Flynn, A. R.; McDaniel, K. A.; Hughes, M. E.; Vogt, D. B.; Jui, N. T. Hydroarylation of Arenes via Reductive Radical-Polar Crossover. J. Am. Chem. Soc. 2020, 142, 9163. (t) Ma, J.; Schäfers, F.; Daniliuc, C.; Bergander, K.; Strassert, C. A.; Glorius, F. Gadolinium Photocatalysis: Dearomative [2+2] Cycloaddition/Ring-Expansion Sequence with Indoles. Angew. Chem. Int. Ed. 2020, 59, 9639. (u) McAtee, R. C.; Noten, E. A.; Stephenson, C. R. J. Arene dearomatization through a catalytic N-centered radical cascade reaction. Nat. Commun. 2020, 11, 2528. (v) Mateos, J.; VegaPeñaloza, A.; Franceschi, P.; Rigodanza, F.; Andreetta, P.; Companyó, X.; Pelosi, G.; Bonchio, M.; Dell'Amico, L. A visible-light Paternò-Büchi dearomatisation process towards the construction of oxeto-indolinic polycycles. Chem. Sci. 2020, 11, 6532. (w) Dong, W.; Yuan, Y.; Xie, X. Zhang, Z. Visible-Light-Driven Dearomatization Reaction toward the Formation of Spiro[4.5]deca-1,6,9-trien-8-ones. Org. Lett. 2020, 22, 9163. (x) Cheng, Y.Z.; Huang, X.-L.; Zhuang, W.-H.; Zhao, Q.-R.; Zhang, X.; Mei, T.-S.; You S.-L. Intermolecular Dearomatization of Naphthalene Derivatives via a Photoredox-Catalyzed 1,2-Hydroalkylation. Angew. Chem. Int. Ed. 2020, DOI: 10.1002/anie.202008358.

(5) (a) Zhu, M.; Zheng, C.; Zhang, X.; You, S.-L. Synthesis of Cyclobutane-Fused Angular Tetracyclic Spiroindolines via Visible-Light-Promoted Intramolecular Dearomatization of Indole Derivatives. J. Am. Chem. Soc. 2019, 141, 2636. (b) Oderinde, M. S.; Mao, E.; Ramirez, A.; Pawluczyk, J.; Jorge, C.; Cornelius, L. A. M.; Kempson, J.; Vetrichelvan, M.; Pitchai, M.; Gupta, A.; Gupta, A. K.; Meanwell, N. A.; Mathur, A.; Dhar, T. G. M. Syn- thesis of Cyclobutane-Fused Tetracyclic Scaffolds via Visible-Light Photocatalysis for Building Molecular Complexity. J. Am. Chem. Soc. 2020, 142, 3094. (c) Rolka, A. B.; Koenig, B. Dearomative Cycloadditions Utilizing an Organic Photosensitizer: An Alternative to Iridium Catalysis. Org. Lett. 2020, 22,5035 .

(6) (a) Strieth-Kalthoff, F.; Henkel, C.; Teders, M.; Kahnt, A.; Knolle, W.; Gómez-Suárez, A.; Dirian, K.; Alex, W.; Bergander, K.; Daniliuc, C. G.; Abel, B.; Guldi, D. M.; Glorius, F. Discovery of Unforeseen Energy-TransferBased Transformations Using a Combined Screening Approach. Chem 2019, 5, 2183. (b) Zhu, M.; Huang, X.-L.; Xu, H.; Zhang, X.; Zheng, C.; You, S.-L. Visible-Light-Mediated Synthesis of Cyclobutene-Fused Indolizidines and Related Structural Analogs. CCS Chem. 2020, 2, 652. (c) Ha, S.; Lee, Y.; Kwak, Y.; Mishra, A.; Yu, E.; Ryou, B.; Park, C.-M. Alkyne-Alkene [2+2] cycloaddition based on visible light photocatalysis. Nat. Commun. 2020, 11, 2509.

(7) (a) Arai, N.; Ohkuma, T. Stereoselective Construction of Methylenecyclobutane-Fused Indolines through Photosensitized [2+2] Cycloaddition of Allene-Tethered Indole Derivatives. Org. Lett. 2019, 21, 1506. Addition and correction: Org. Lett. 2019, 21, 8507. (b) Arai, N.; Ohkuma, T. Stereoselective preparation of methylenecyclobutane-fused angular tetracyclic spiroindolines via photosensitized intramolecular $[2+2]$ cycloaddition with allene. Tetrahedron Lett. 2019, 60, 151252.

(8) For selected reviews: (a) Abe, M. Diradicals. Chem. Rev. 2013, 113, 7011. (b) Strieth-Kalthoff, F.; James, M.J.; Teders, M.; Pitzer, L.; Glorius, F. Energy transfer catalysis mediated by visible light: principles, applications, directions. Chem. Soc. Rev. 2018, 47, 7190. (c) Zhou, Q.-Q.; Zou, Y.-Q.; Lu, L.-Q.; Xiao, W.-J. Visible-light-induced organic photochemical reactions via energy transfer pathways. Angew. Chem. Int. Ed. 2019, 58, 1586. (d) Sherbrook, E. M.; Yoon, T. P. Asymmetric Catalysis of Triplet-State Photoreactions. Photochemistry 2019, 46, 432.

(9) For selected reviews on the synthesis of azetidines: (a) Cromwell, N. H.; Phillips, B. The Azetidines. Recent Synthetic Developments. Chem. Rev. 1979, 79, 331. (b) Brandi, A.; Cicchi, S.; Cordero, F. M. Novel Syntheses of Azetidines and Azetidinones. Chem. Rev. 2008, 108, 3988. (c) Richardson, A. D.; Becker, M. R.; Schindler, C. S. Synthesis of azetidines by aza PaternòBüchi reactions. Chem. Sci. 2020, DOI: 10.1039/d0sc01017k. For recent examples on aza Paternò-Büchi reactions: (d) Sakamoto, R.; Inada, T.; Sakurai, S.; Maruoka, K. [2 + 2] Photocycloadditions between the CarbonNitrogen Double Bonds of Imines and Carbon-Carbon Double Bonds. Org. Lett. 2016, 18, 6252. (e) Kumarasamy, E.; Kandappa, S. K.; Raghunathan, R; Jockusch, S.; Sivaguru, J. Realizing an Aza Paternò-Büchi Reaction. Angew. Chem., Int. Ed. 2017, 56, 7056. (f) Becker, M. R.; Richardson, A. D.; Schindler, C. S. Functionalized azetidines via visible light-enabled aza Paternò-Büchi reactions. Nat. Commun. 2019, 10, 5095. (g) Becker, M. R.; Wearing, E. R.; C. S. Schindler, Synthesis of azetidines via visible light-mediated intermolecular $[2+2]$ photocycloaddition. ChemRxiv Preprint. https://doi.org/10.26434/chemrxiv.11832993.v1

(10) During the preparation of this manuscript, Yoon and coworkers published divergent photocatalytic reactions of $a$-ketoesters towards either Paternò-Büchi cycloadditions or allylic functionalization via triplet sensitization or photoredox catalysis. Zheng, J.; Dong, X.; Yoon, T. P. Divergent Photocatalytic Reactions of $\alpha$-Ketoesters Under Triplet Sensitization and Photoredox Conditions. ChemRxiv Preprint. http://doi.org/10.26434/chemrxiv.12611459.v1 


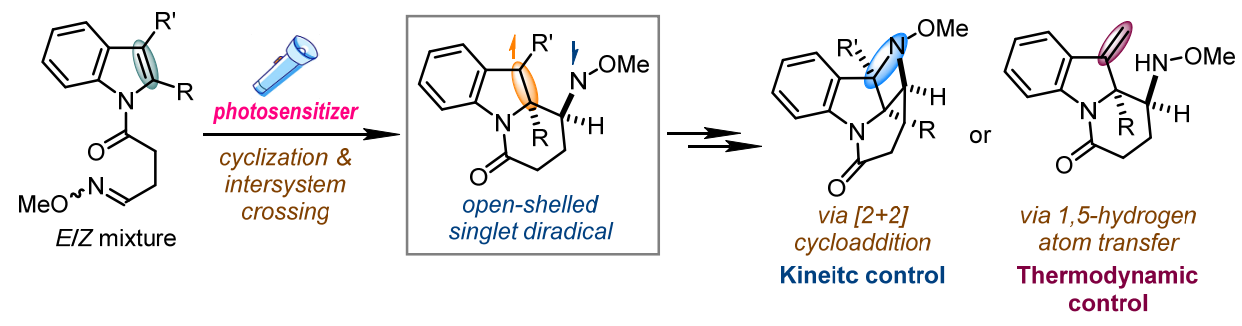

